\title{
Corrosion Study for the Effluent Treatment Facility Chrome (VI) Reductant Solution Using 304 and 316L Stainless Steel
}

\author{
J. B. Duncan \\ CH2M HILL Hanford Group, Inc. \\ Richland, WA 99352 \\ U.S. Department of Energy Contract DE-AC27-99RL14047 \\ $\begin{array}{lll}\text { EDT/ECN: } & \text { DRF } & \text { UC: } \\ \text { Cost Center: } & 7 S 110 & \text { Charge Code: } \\ \text { B\&R Code: } & & \text { Total Pages: } 19\end{array}$
}

Key Words: Emluent Treatment Facility, oxidation reduction potential, cyclic potentiodynamic polarization, test, solutions, linear polarization resistance, open circuit potential, secondary waste receiving tank, spent resin, 304 and 316L stainless steel, chrome (VI), chrome (III), sodium sulfate, sodium metabisulfite, WSFS, groundwater pump, plume, DOWEX, RPP-RPT-32207

Abstract: The Emluent Treatment Facility has developed a method to regencrate spent resin from the groundwater pump and treat intercepting chrome (VI) plumes (RPP-RPT-32207, Laboratory Study on Regeneration of Spent DOWEX 21K 16-20 Mesh Ion Exchange Resin). Subsequent laboratory studies have shown that the chrome (VI) may be reduced to chrome (III) by titrating with sodium metabisulfite to an oxidation reduction potential (ORP) of $+280 \mathrm{mV}$ at a pll of 2 . This test plan describes the use of cyclic potentiodynamic polarization and linear polarization techniques to ascertain the electrochemical corrosion and pitting propensity of the 304 and $316 \mathrm{~L}$ stainless steel in the acidified reducing solution that will be contained in either the secondary waste receiver tank or concentrate tank.

TRADEMARK DISCLAIMER. Reference herein to any specific commercial product, process, or service by trade name, trademark, manufacturer, or otherwise, does not necessarily constitute or imply its endorsement, recommendation, or favoring by the United States Government or any agency thereof or its contractors or subcontractors.

Printed in the United States of America. To obtain copies of this document, contact: Document Control Services, P.O. Box 950, Mailstop H6-08, Richland WA 99352, Phone (509) 372-2420; Fax (509) 376-4989.

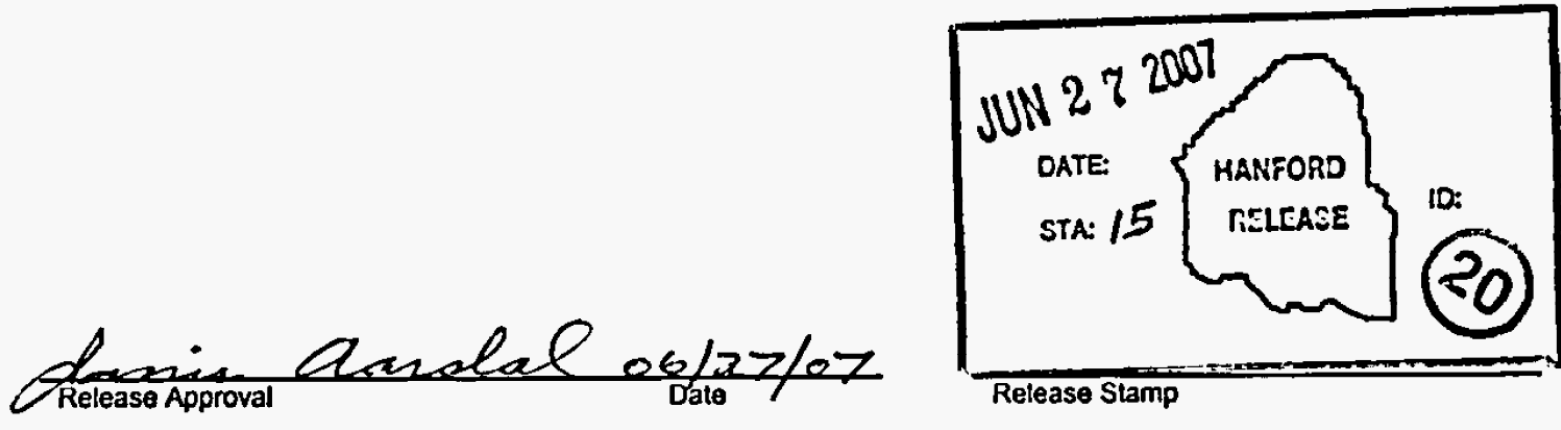

Approved For Public Release 


\title{
Corrosion Study for the Effluent Treatment Facility Chrome (VI) Reductant Solution Using 304 and 316L Stainless Steel
}

\author{
J. B. Duncan \\ CH2M HILL Hanford Group, Inc. \\ R. B. Wyrwas \\ RJ Lee Group, Inc.
}

Date Published

June 2007

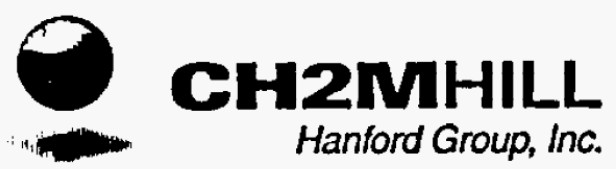

Prepared for the U.S. Department of Energy Office of River Protection

Contract No. DE-AC27-99RL14047

Approved for public relcase; distribution is unlimited 


\section{TABLE OF CONTENTS}

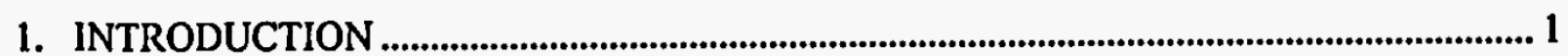

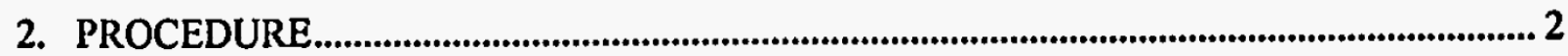

2.1 Quality ControVQuality Assurance............................................................................ 2

2.2 Linear Polarization Resistance........................................................................................... 2

2.3 Cyclic Potentiodynamic Polarization....................................................................................... 3

2.4 Test Solutions................................................................................................................... 5

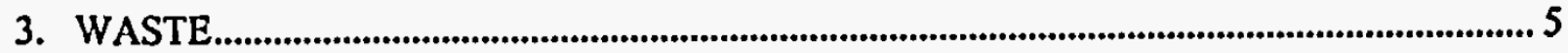

4. DELIVERABLES.............................................................................................................. 5

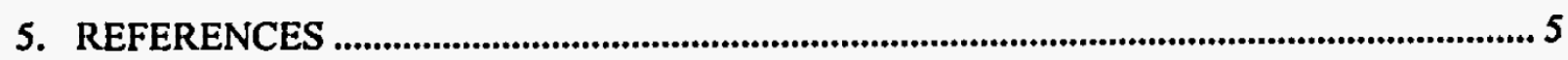

APPENDIX A RCRA Treatability Study Determination Workshect.............................................. 7

APPENDIX B Waste Stream Fact Sheets .......................................................................................... 9

APPENDIX C Compatibility Review................................................................................................ 12

\section{List of Figures}

Figure 1. Oxidation-Reduction Potential $\mathrm{mV}$ versus Reagent Addition............................................ 1

Figure 2. Cyclic Potentiodynamic Polarization Curve. ........................................................................ 4

\section{List of Tables}

Table 1. Test Solutions

\section{List of Acronyms}

CPP cyclic potentiodynamic polarization

ETF Emuent Treatment Facility

LPR lincar polarization resistance

OCP open circuit potential

ORP oxidation reduction potential

SWRT secondary waste receiving tank 


\section{INTRODUCTION}

The Effluent Treatment Facility (ETF) has developed a method to regenerate spent resin from the ground water pump and treat intercepting chrome (VI) plumes (RPP-RPT-32207, Laboratory Study on Regeneration of Spent DOWEX' 21 K 16-20 Mesh Ion Exchange Resin). Subsequent laboratory studics have shown that the chrome (VI) may be reduced to chrome (III) by titrating with sodium metabisulfite to an oxidation reduction potential (ORP) of $+280 \mathrm{mV}$ at a pH of 2 . Equations 1 and 2 give the stoichiometric relationships involved in the reactions (Pollution Prevention and Control Technology for Plating Operations, Cushnie 1994).

$$
\mathrm{Na}_{2} \mathrm{~S}_{2} \mathrm{O}_{5}+\mathrm{H}_{2} \mathrm{O} \rightarrow 2 \mathrm{NaHSO}_{3}
$$

Then

$$
3 \mathrm{NaHSO}_{3}+2 \mathrm{H}_{2} \mathrm{CrO}_{4}+3 \mathrm{H}_{2} \mathrm{SO}_{4} \rightarrow \mathrm{Cr}_{2}\left(\mathrm{SO}_{4}\right)_{3}+\mathrm{SH}_{2} \mathrm{O}+3 \mathrm{NaHSO}_{4}
$$

Figure 1 shows the ORP versus the sodium metabisulfite reagent addition to achieve the reduced chrome (III) specics (pII and ORP Control for Removing Chrome from Plant Effluent, ADS 3300-02/rev.A).

Figure 1. Oxidation-Reduction Potential $\mathrm{mV}$ versus Reagent Addition.

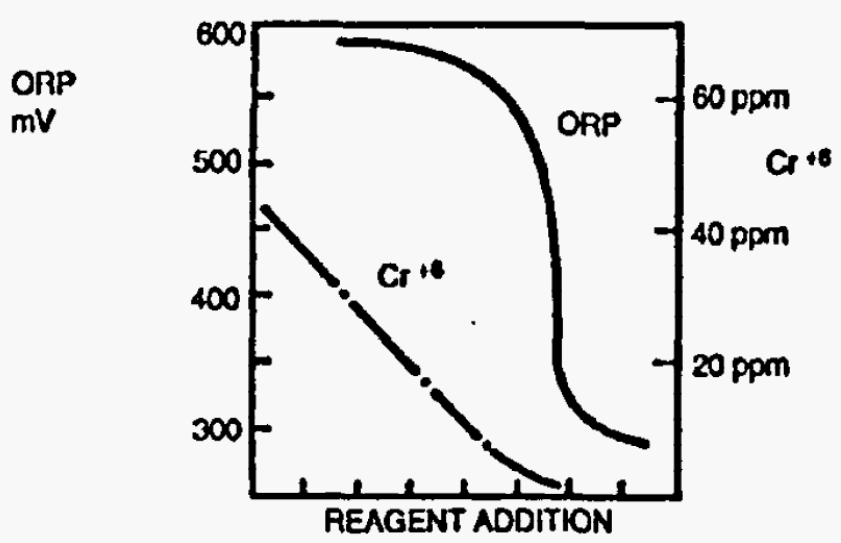

To regenerate the spent ion exchange resin, several bed volumes of $0.5 \mathrm{M}$ sodium sulfate will be used to displace the chrome (VI) from the resin. This will result in a large volume of sodium sulfate and chrome (VI). The chrome (VI) will then be reduced to chrome (III) at a pH of 2 with sodium metabisulfite as described above. The reduction will take place in either the secondary waste receiving tank (SWRT) or the concentrate tank. The materials of construction for the SWRT is 304 stainless stecl and the concentrate tank is $316 \mathrm{~L}$ stainless stecl.

\footnotetext{
' DOWEX ${ }^{\text {Th }}$ is a registered trademark of Dow Chemical Company, Midland, Michigan.
} 


\section{RPP-PLAN-34065, Rev. 0}

This test plan describes the use of cyclic potentiodynamic polarization and linear polarization techniques to ascertain the electrochemical corrosion and pitting propensity of the 304 and $316 \mathrm{~L}$ stainless steel in the acidified reducing solution that will be containcd in either the SWRT or concentrate tank.

The customer has made the determination that this cffort does not constitute a treatability study and has completed the Treatability Study Determination Workshect to that effect (Appendix A).

\section{PROCEDURE}

The electrochemical corrosion testing will encompass allowing the test coupon to cquilibrate with the test solution, and the use of both lincar polarization resistance (LPR) and cyclic potentiodynamic polarization (CPP) techniques.

\subsection{QUALITY CONTROL/QUALITY ASSURANCE}

This effort will be conducted under ATS-MP-1032, 222-S Laboratory Quality Assurance Plan. Before test scans, the instrument response will be tested using ASTM G5-94, Standard Reference Test Method for Making Potentiostatic and Potentiodynamic Anodic Polarization Measurements.

The following discussion of LPR and CPP is extracted from An Introduction to Electrochemical Corrosion Testing for Practicing Engineers and Scientists (Tait 1994).

\subsection{LINEAR POLARIZATION RESISTANCE}

Linear polarization uses a very small spectrum of overpotential from the open circuit potential (OCP) of the material in question. The coupon is scanned $\pm 20 \mathrm{mV}$ either side of the OCP.

To calculate corrosion currents and therefore corrosion rates from LPR data, a slope is derived that corresponds to the corrosion resistance.

$$
R_{p}=\text { change in potential } / \text { change in current density }=\Delta E / \Delta i
$$

The units are volts/amps $/ \mathrm{cm}^{2}$, and volts/amps is ohms, therefore the units are ohms $\mathrm{cm}^{2}$.

After the LRP determination is complete, the next calculation is to determine the corrosion current or $i_{\text {corr, }}$ which is calculated by:

$$
i_{c o r r}=\left[1 /\left(2.303 R_{p}\right)\right]\left[\left(\beta_{a} * \beta_{c}\right) /\left(\beta_{a}+\beta_{c}\right)\right]
$$


RPP-PLAN-34065, Rev. 0

where

$\beta_{a}=$ the anodic Tafel slope in volts/decade of current density, and

$\beta_{c}=$ the cathodic Tafel slope in volts/decade current density.

The quantity $\left(\beta_{\mathrm{a}} * \beta_{\mathrm{c}}\right) /\left(\beta_{\mathrm{a}}+\beta_{\mathrm{c}}\right)$ is referred to as the Tafel constant.

The units for $i_{\text {corr }}$ are $\mathrm{mA} / \mathrm{cm}^{2}$. After calculating the value for $\mathrm{i}_{\text {corr, }}$ the corrosion rate in mils/ycar (mpy) is calculated by the following:

$$
M P Y=i_{\text {corr }}(\Lambda)(1 / \rho)(\epsilon)
$$

whore

$$
\begin{aligned}
\Lambda= & \text { a combination of several terms and is } \\
& 1.2866 \mathrm{E} 05[\mathrm{cquivalents} \cdot \mathrm{scc} \cdot \mathrm{mils}] /[\mathrm{coulombs} \cdot \mathrm{cm} \cdot \mathrm{ycars}] \\
\rho= & \text { metal density in } \mathrm{g} / \mathrm{cm}^{3} \\
\epsilon= & \text { equivalent wcight in g/equivalent. }
\end{aligned}
$$

For iron, the density is $7.87 \mathrm{~g} / \mathrm{cm}^{3}$ and the cquivalent weight is $27.56 \mathrm{~g} /$ cquivalent.

The main advantage of using LPR is that it is a nondestructive test and can be repeatedly used on the same test electrode to continuously monitor corrosion for long periods. A limitation of LPR is that the technique can only measure general corrosion rates and thus can not be used to determine if localized corrosion such as pitting or crevice corrosion is present or information around kinetics controlling the rate of corrosion.

\subsection{CYCLIC POTENTIODYNAMIC POLARIZATION}

Cyclic potentiodynamic polarization curves are an extension of the potentiodynamic polarization scan. The CPP reverses at a given potential or current density as described in the ASTM method ASTM G61-86, Standard Test Method for Conducting Cyclic Potentiodynamic Polarization Measurements for Localized Corrosion Susceptibility of Iron-, Nickel-, or CobaltBased Alloys.

The CPP curve is a destructive test as opposed to the LPR, in that it will scan from $-250 \mathrm{mV}$ versus OCP through a designated potential (or current density) of approximately $+1000 \mathrm{mV}$ versus OCP before reversing. The information gathered from the scan includes the following:

a. Electrochemical corrosion (mpy) calculated from the Tafel region of the scan.

b. $\mathrm{E}_{\mathrm{pp}}$, the primary passivation potential, which is the potential after which current either decreases or becomes essentially constant over a finite potential range.

c. $E_{b}$, the breakdown potential, where the current increases with increasing potential. 
d. Positive hysteresis, where the curve reverses at a higher current density indicating pit growth.

e. Negative hysteresis, where the curve reverses at lower current density indicating no pit growth.

f. $\mathrm{E}_{\mathrm{rp}}$, the repassivation potential, essentially a new OCP given the change in potential and the effect on the double layer.

Figure 2 shows an example of a CPP curve that does not indicate pitting propensity. A description of the graph is as follows:

The scan begins at the point below A and goes through the OPC (this is the potential the steel is at electrochemical equilibrium) which is located at $\mathrm{B}$. The curve proceeds to $\mathrm{C}$, which is a breakdown potential (the protective chemical film over the steel has broken apart and the steel is attacked). The curve is reversed at $\mathrm{D}$ (this is a predetermined point by the scientist). Because of chemical reactions that occur during scanning, a new OCP is formed, located at E. With this curve, the return scan between $\mathrm{D}$ and $\mathrm{E}$ is at lower current than from $\mathrm{B}$ to $\mathrm{C}$ to $\mathrm{D}$. This indicates no pitting propensity for this sample.

Figure 2. Cyclic Potentiodynamic Polarization Curve.

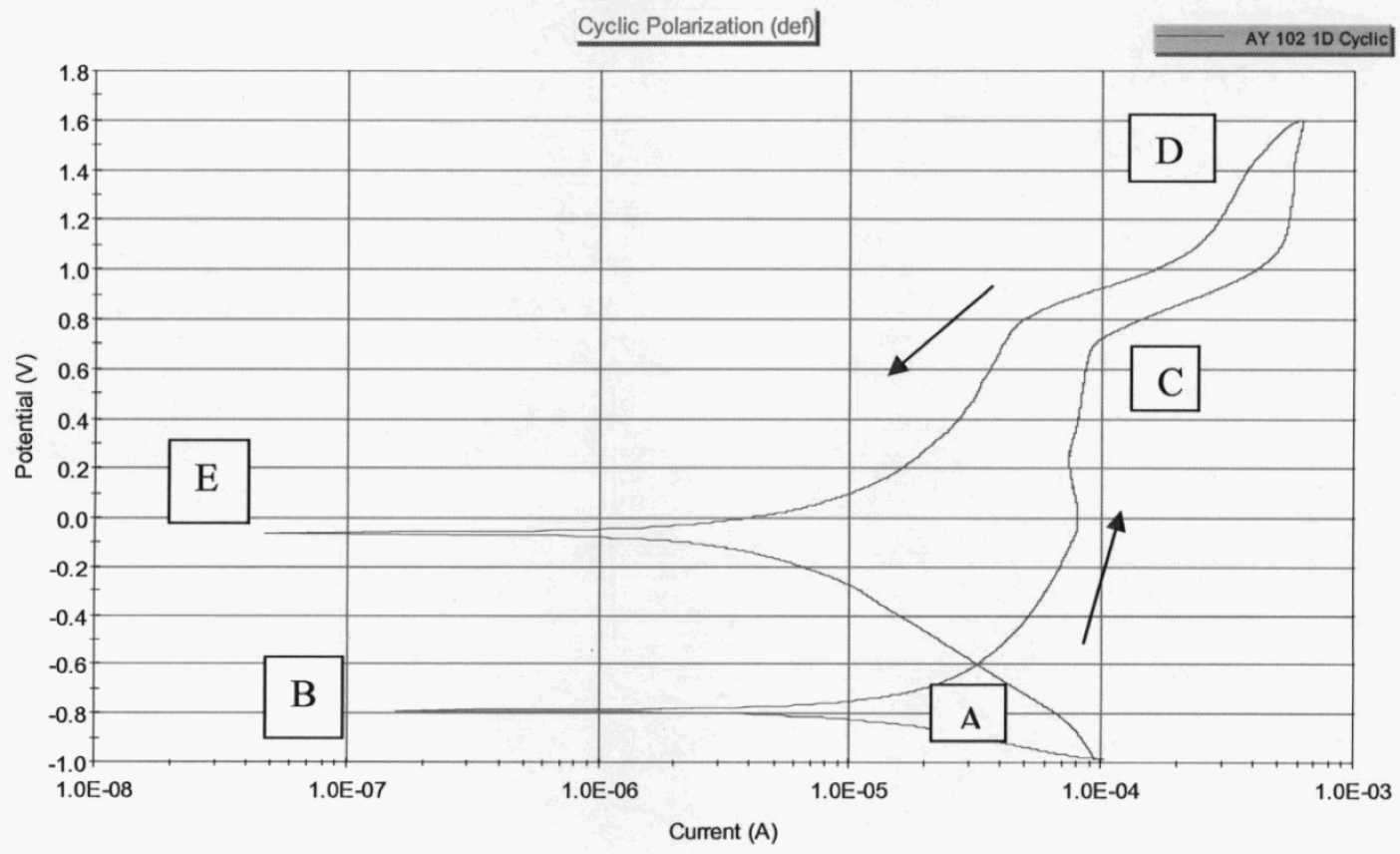




\section{$2.4 \quad$ TEST SOLUTIONS}

Table 1 indicates the following test solutions (using deionized water) will be tested against the 304 and 316L stainless stcel coupons:

Table 1. Test Solutions

\begin{tabular}{|c|c|c|c|c|}
\hline $\begin{array}{c}\text { Test Solution } \\
\left(\mathrm{T}=\mathbf{1 4 0}^{\circ} \mathrm{F}\right)\end{array}$ & Sodium Sulfate & Chrome (VI) & Sulfuric Acid & $\begin{array}{c}\text { Sodium } \\
\text { Metabisulfite }\end{array}$ \\
\hline Test Solution 1 & $4 \%$ & $50 \mathrm{ppm}$ & pll 2 & $300 \mathrm{ppm}$ \\
\hline Test Solution 2 & $4 \%$ & $50 \mathrm{ppm}$ & pII 2 & NA \\
\hline Test Solution 3 & NA & NA & pHI 2 & NA \\
\hline
\end{tabular}

All weighing/handling of Chrome (VI) will be carricd out in a chemical hood.

Also, all Chrome (VI) solutions will be converted to Chrome (III) with sodium metabisulfite.

The test solution concentrations are based on the concentrations found to be associated with the regeneration of DOWEX 21K XLT 16-20 resin. The sodium metabisulfite concentrations were determined during the laboratory cffort under the test plan entitled RPP-PLAN-32738, Test Plan for the Effluent Treatment Facility to Reduce Chrome (VI) to Chrome (III) in the Secondary Waste Stream.

\section{WASTE}

Waste will be managed in accordance with ATS-LO-110-129, ATS Waste Collection of Nonradioactive Materials. Waste Stream Fact Shects and Compatibility Reviews are presented in Appendixes A and B, respectively.

\section{DELIVERABLES}

A CH2M HILL Hanford Group, Inc. supporting document will be issued within 30 days of complction of the test plan.

\section{REFERENCES}

Application Data Shect, ADS 3300-02/rev.A, August 2004, pH and ORP Control for Removing Chrome from Plant Effluent, in Mctals and Mineral Industry, Emerson Process Management, http://www.emersonprocess.com/raihome/documents/Liq_AppData 330002.pdf.

ASTM G5-94, 1994 (Reapproved 1999), Standard Reference Test Method for Making Potentiostatic and Potentiodynamic Anodic Polarization Measurements, ASTM International, West Conshohocken, Pennsylvania. 


\section{RPP-PLAN-34065, Rev. 0}

ASTM G61-86, 1986 (Reapproved 2003), Standard Test Method for Conducting Cyclic Potentiodynamic Polarization Measurements for Localized Corrosion Susceptibility of Iron-, Nickel-, or Cobalt-Based Alloys, ASTM International, West Conshohocken, Pennsylvania.

ATS-LO-110-129, ATS Waste Collection of Nonradioactive Materials, Rev. F-0, CH2M HILL Hanford Group, Inc., Richland, Washington.

ATS-MP-1032, 2007, 222-S Laboratory Quality Assurance Plan, Rev. 0, CH2M HILL Hanford Group, Inc., Richland, Washington.

Cushnic, G. C., 1994, Pollution Prevention and Control Technology for Plating Operations, National Center for Manufacturing Sciences, Ann Arbor, Michigan.

RPP-RPT-32207, 2007, Laboratory Study on Regeneration of Spent DOWEX 21K 16-20 Mesh Ion Exchange Resin, Rcv. 0, CH2M HILL Hanford Group, Richland, Washington.

Tait, W. S., 1994, "An Introduction to Electrochemical Corrosion Testing for Practicing Engineers and Scientists," PairODocs Publications, Racine, Wisconsin. 
RPP-PLAN-34065, Rev. 0

\section{APPENDIX A}

RCRA Treatability Study Determination Worksheet 


\section{RCRA Treatability Study Determination Worksheet}

Resource Conservation and Recovery Act of 1976 (RCRA)
Corrosion Study for the Effluent Treatmat Facility Chrome (UI)
Reductant Solution Using 304 and $316 \mathrm{~L}$ stainless steel.

1. Documentwork Instruction Title: Reductant Solutiod Using 304 and $316 \mathrm{~L}$ stainless steel.

Document No.: RPP-PLAN-34065, Rev $\varnothing$

2. Is the media being submitted for study a dangerous or mixed waste?

"Dangerous waste" means a waste identified in WAC 173-303-070 through 173-303-100 as dangerous. extremely hazardous or mixed waste.

If the answer to Qucstion 2 is "yes" then procced to Question 3 below. If the answer is "no," the study is not a RCRA Treatability Study. Proceed to Question 5 and answer "No."

3. Does the study involve treatment of the dangerous waste? In RCRA, dangerous waste treatment is any physical, chemical, or biological processing of dangerous waste to make it:
a. nondangerous or less dangerous,
b. safer for transport
c. amenable for energy or material resource recovery
d. amenable for storage, or reduced in volume, with the exception of compacting. repackaging, and sorting as allowed under WAC 173-303-400(2) and 173-303-600(3).

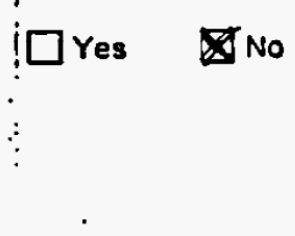

If the answer is "yes" to any one of the above in Question 3, then the waste is being treated. Continue to Question 4.

If the answer is "no" to all of the above in Question 3, then the waste is not being treated and the study is not . a RCRA Treatability Study. Proceed to Question 5 and answor "No."

4. Is the dangerous waste being subjected to a treatment process to determine one or more of the following:
a. Whether the waste is amenable to the treatment process?
b. What pretreatment (if any) is required?
c. Optimal Process conditions needed to achieve the desired treatment?
d. Etficiency of a treatment process for a specific waste or wastes?
e. Characteristics and volumes of residuals from a particular treatment process?
Yes
No

If all answers to Question 4 are "no," then the study is not a RCRA Treatability Study. Proceed to Question 5 : and answer "No."

If "yes" is answered to any part of Question 4, the study is a RCRA Treatability Study. Proceed to Question 5 anḍ answer "Yes."

5. Based on the answers to Questions $2-4$, is the study a RCRA treatability study as defined in WAC 173-303-040?

6. If the answer to Question 5 is "yes," has the one-time Ecology notification been made? Letter Reference:
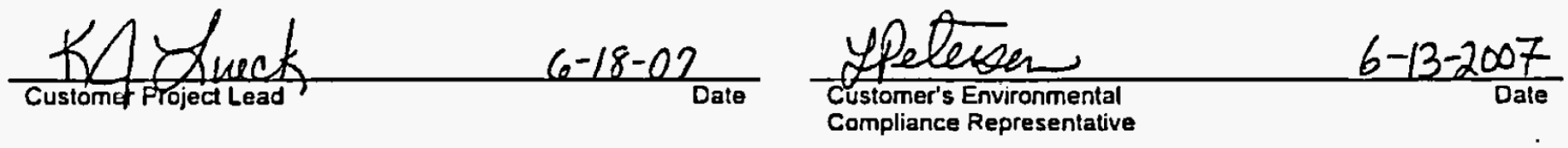
RPP-PLAN-34065, Rev. 0

APPENDIX B

Waste Stream Fact Sheets 
222-S LABORATORY DEVELOPMENTAL METHOD WASTE STREAMI FACT SHEET

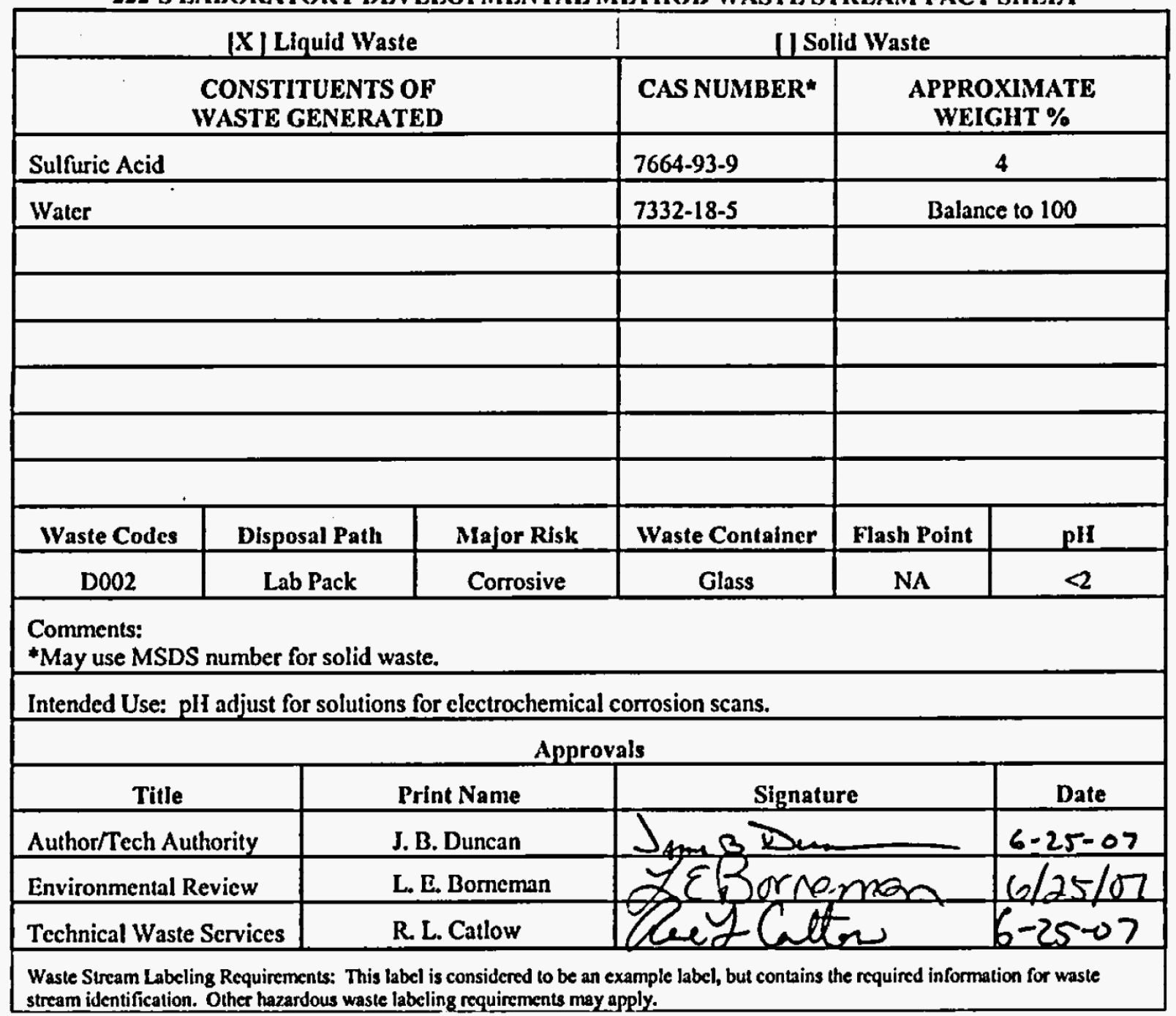

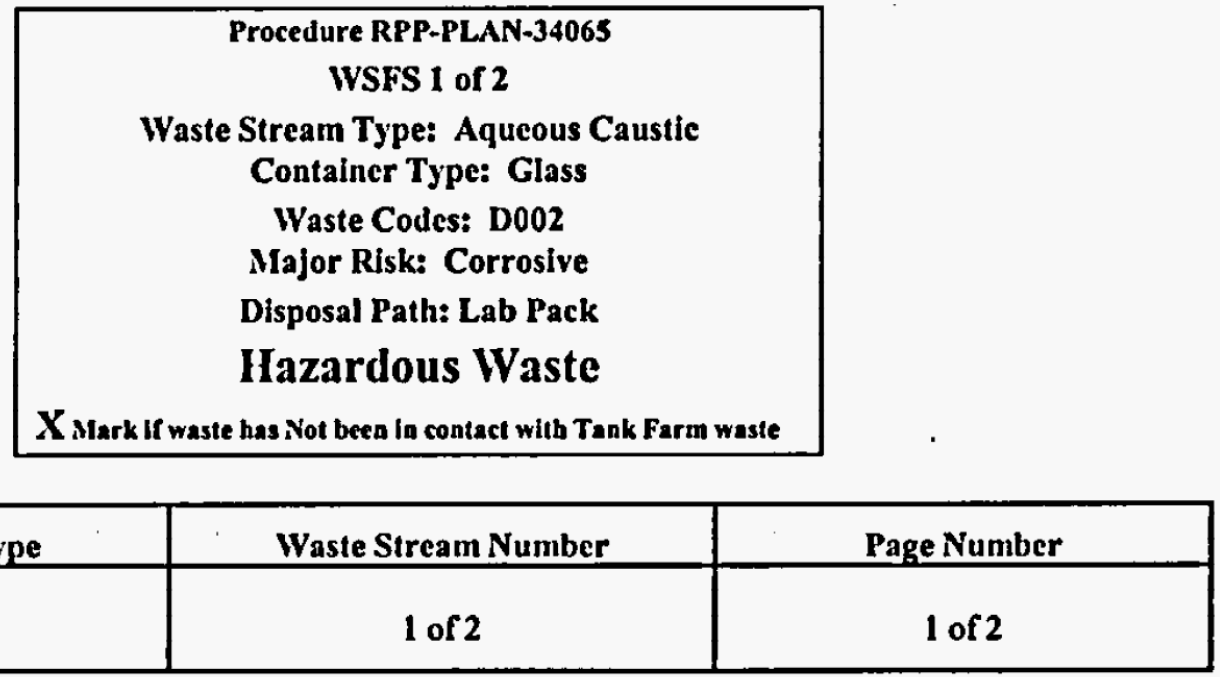


RPP-PLAN-34065, Rev. 0

222-S LABORATORY DEVELOPMENTAL METHOD IVASTE STREAM FACT SHEET

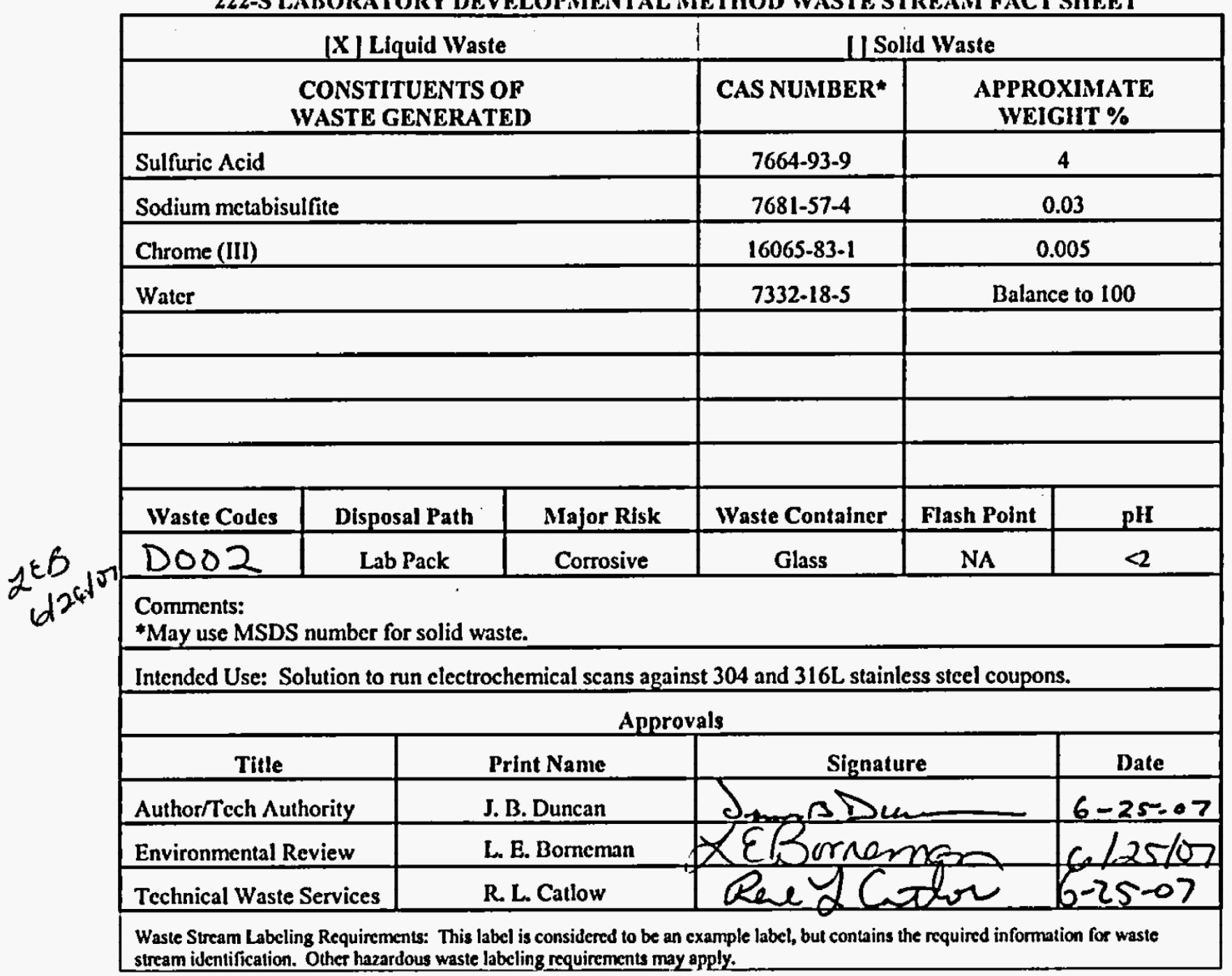

\begin{tabular}{|c|c|c|}
\hline & $\begin{array}{r}\text { Procedure RPP-PLAN-34065 } \\
\text { WSFS } 1 \text { of } 2 \\
\text { Waste Stream Type: Aqueous C } \\
\text { Container Type: Glass } \\
\text { Waste Codes: D002 } \\
\text { Major Risk: Corrosive } \\
\text { Disposal Path: Lab Pack } \\
\text { Hazardous Waste } \\
\text { X sark if waste has Not been in contact with Tan }\end{array}$ & \\
\hline Waste Stream Type & Waste Stream Number & Page Number \\
\hline Aqueous Acid & 2 of 2 & 2 of 2 \\
\hline
\end{tabular}


RPP-PLAN-34065, Rev. 0

\section{APPENDIX C}

Compatibility Review 


\section{Compatibility Review}

Compatibility, in this case, means that two or more substances can be mixed with no adverse effects occurring over an extended period. Incompatibility means contact of two or more substances could result in an explosion, an unexpected rapid evolution of gases, or the cmission of substances that are highly toxic and/or flammable.

PROCEDURE NUMBER: RPP-PLAN-34065

CHEMICALS OF CONCERN IN ANALYSIS/NASTE STREAMI (WHERE REACTIVITY/CONCENTRATION POSE A POTENTIAL, CONPATIBILITY ISSUE)

MAXIMUM CONCENTRATION

Sodium Hydroxide $10 \%$

COMPATIBILITY HAZARDS, INCLUDING SPECIAL STORAGE REQUIREMENTS, POSSIBLE REACTIONS, AND RESULTS OF MIXING INCOMPATIBLE WASTE STREAMS:

Base solution ( $\mathrm{pH}>12.5$ ) and corrosive.

RECOMMENDED WASTE STREAMS:

Aqueous basic corrosive waste

CONTAINER(S) MATERIAL:

Glass

REFERENCE DOCUMENTS USED IN COMPATIBILITY STUDY:

NIOSI Pocket Guide to Chemical Hazards

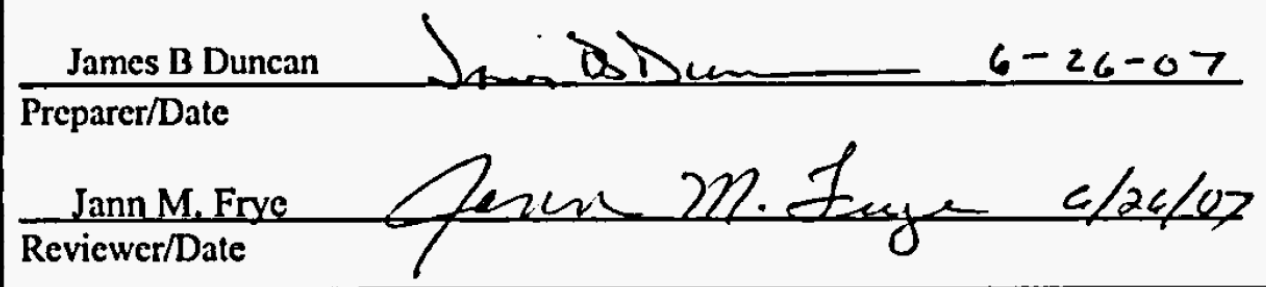




\section{Compatibility Review}

Compatibility, in this case, means that two or more substances can be mixed with no adverse effects occurring over an extended period. Incompatibility means contact of two or more substances could result in an explosion, an unexpected rapid evolution of gases, or the cmission of substances that are highly toxic and/or flammable.

PROCEDURE NUMBER: RPP-PLAN-34065

CHEMICALS OF CONCERN IN ANALYSIS/WASTE STREAM

(WHERE REACTIVITY/CONCENTRATION

POSE A POTENTIAL, COMPATIBII,ITY ISSUE)

MAXIMUM CONCENTRATION

Sodium Sulfate

$7 \%$

\section{COMIPATIBILITY HAZARDS, INCLUDING SPECIAL STORAGE REQUIREMENTS, POSSIBLE REACTIONS, AND RESULTS OF MIIXING INCOMIPATIBLE WASTE STREAMIS:}

Sodium sulfate is a hygroscopic solid. The solid is incompatible with strong acids, aluminum, and magnesium. In this procedure it is used as a solution in water and in this form does not have incompatibility issues.

\section{RECOMMENDED IVASTE STREAMS:}

Collect in a separate waste stream or may be combined with a basic aqueous waste stream of sodium hydroxide.

\section{CONTAINER(S) MATERIAL:}

Glass

\section{REFERENCE DOCUMENTS USED IN COMPATIBILITY STUDY:}

NIOSH Pocket Guide to Chemical Hazards, Sigma Aldrich MSDS, Hanford \#036357.
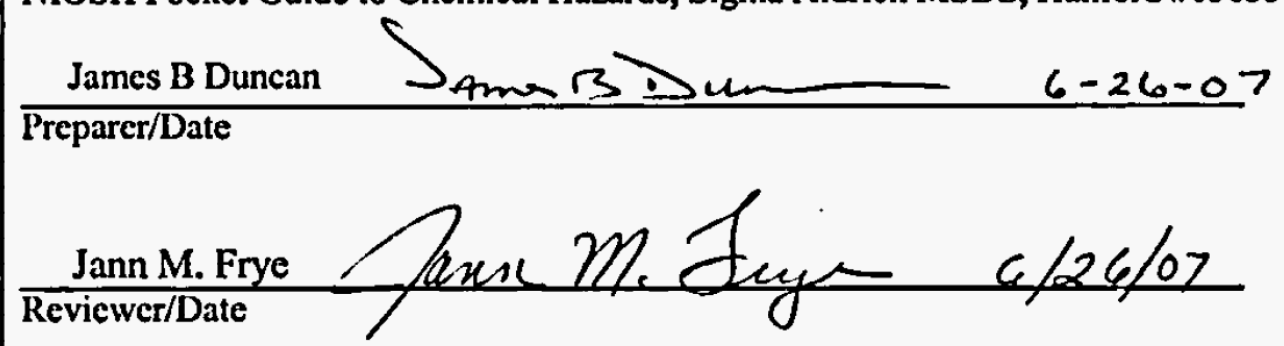


\section{Compatibility Review}

Compatibility, in this case, means that two or more substances can be mixed with no adverse effects occurring over an extended period. Incompatibility means contact of two or more substances could result in an explosion, an unexpected rapid cvolution of gases, or the cmission of substances that are highly toxic and/or flammable.

PROCEDURE NUMBER: RPP-PLAN-34065

CHEMICALS OF CONCERN IN ANALYSIS/WASTE STREAM

(WHERE REACTIVITY/CONCENTRATION

POSE A POTENTIAL, COMIPATIBIL,ITY ISSUE)

MAXIMIUM CONCENTRATION

Sulfuric Acid

$1 \mathrm{~N}$

COMPATIBILITY HAZARDS, INCLUDING SPECIAL STORAGE REQUIREMENTS, POSSIBLE REACTIONS, AND RESULTS OF MIXING INCOMPATIBLE WASTE STREAMS:

Acid solution ( $\mathrm{pH}<2)$ and corrosive. Avoid chlorates, carbides, fulminates, water, powdered metals [Note: Reacts violently with water with evolution of heat. Corrosive to metals.]

\section{RECOMMENDED WASTE STREAMS:}

Aqueous acidic corrosive waste

CONTAINER(S) MATERIAL: Glass

\section{REFERENCE DOCUMENTS USED IN COMPATIBILITY STUDY:}

NIOSH Pocket Guide to Chemical Hazards

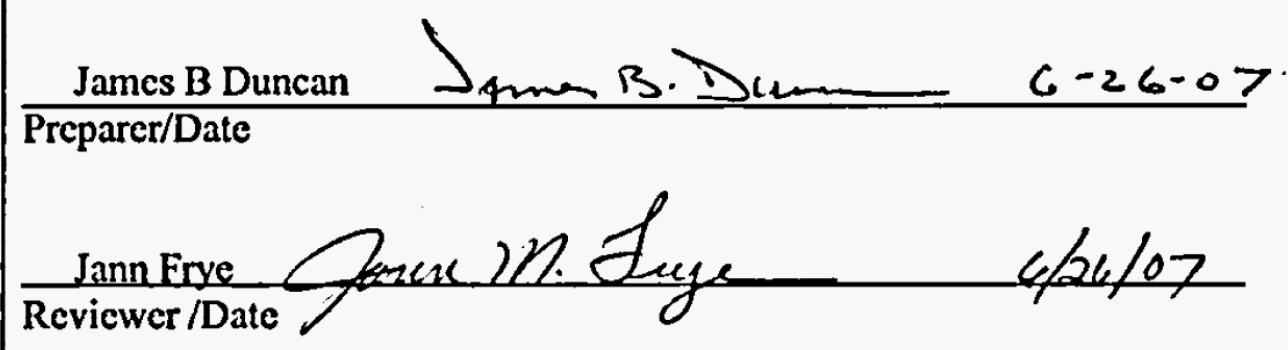

